\title{
Bonding through the mask
}

\author{
PRIYAM SAIKIA
}

\begin{abstract}
The appearance of healthcare professionals and their interaction with patients has always been the scaffolding of the relationship between the caregiver and patient. The Covid-19 pandemic has challenged this with its need for masking and distancing. The duty bound frontline worker in the midst of the personal crisis brought about by this pandemic has undergone hitherto unknown experiences described here.
\end{abstract}

Keywords: Masks, Covid-19, healthcare workers, mental health, patient deaths

Around a year ago, I was posted as the in-charge of a Covid19 Intensive Care Unit (ICU). I glowed with pleasure, as I felt I was the chosen one; or maybe I was simply excited at facing something I had never prepared for. However, the excitement died down rather soon. I was becoming more irritable, maybe because of the separation from my family. I used to live alone, as my family was in a different city owing to my wife's job. Maybe also because I spent the longest time with the most critically ill of patients and then had to see most of them succumb; or maybe just because I saw no end to the pandemic.

By the time, the first wave peaked, I had attended to around 300 critically ill patients. We have a system of uploading the image and details of a newly admitted patient onto a digital platform so that all the attending staff can access the details when the need arises. I still remember the face of the aged person dressed in a traditional style; with a peaceful smile and with her eyes enlarged through the high powered lenses, being shifted from the receiving area to the Covid ward. I knew from my friends that the patient had devoted her whole life to the education of young children. She was admitted into the ICU a few days later. As I found her

Authors: Priyam Saikia (saikia.priyam80@gmail.com), Assistant Professor, Department of Anaesthesiology and Critical Care, Gauhati Medical College and Hospital, Guwahati, Assam, 781019 INDIA

To cite: Saikia P. Bonding through the mask. Indian J Med Ethics. Published online first on August 23, 2021.DOI: 10.20529/IJME.2021.062

Manuscript Editor: Rakhi Ghoshal

(c) Indian Journal of Medical Ethics 2021 dyspneic in the ICU bed, I took an extra pillow from the nursing station to provide a back support. She held my hand softly and despite being breathless, thanked me in a calm voice for my help. That pair of bright, piercing eyes beamed right into to my soul as she held my hand and said a few prayers for me and the whole world. I nodded, smiled and went back to the daily round, just like any another day. Gradually the oxygen support had to be increased, and, one day we tried to support her through non-invasive ventilation. The ventilator was state of the art, we all knew our latest management strategies, and we had all the drugs which the most advanced countries were struggling to obtain. But, nothing could satiate the hunger for some fresh air and we had no other option but to put her into a drug-induced sleep and on a ventilator. The person did not survive even with external oxygen support. When we lost that patient, I stood nearby and thought, "My father is a teacher, so is this person. Despite devoting her whole life to one of the noblest causes, here lie her mortal remains. Is this death fair?"

This was not a one-off incident. The Covid-19 death rate kept rising day by day, including the younger sister of a nurse, a state level athlete, a stern bureaucrat, a new mother, a young child. I soon realised the disease does not discriminate between people by age or profession. At one point of time, I no longer wanted to be there and was filled with self-doubt. During the peak of the pandemic, even though my family had joined me and we were preparing to welcome our second baby, I was still not my former self.

After exhausting the six months of maternity leave permitted to Indian working women, I took my wife back to her place of work, $300 \mathrm{kms}$ away from my workplace. And that old emptiness came back. After a year-long battle, the number of patients in the Covid-19 ICU was coming down. I still had a sense of melancholy in me. I was not sure who I was and what I was supposed to be. A failing father, or husband or a doctor failing his patients?

I longed for my family once more. Maybe that is the reason why I started to discuss family ties with my patients. Or, maybe because they longed for a dear one in those hard times, or simply because I now had more time for each patient.

One morning, my mood turned gloomy the moment I entered the Covid ICU as my visors got misted. Cursing the weather and my luck, I opened the door and went to the first patient 
who had turned Covid-negative the previous day. He had come in ten days, earlier with a life threatening arrhythmia but become stable after anti-arrhythmic medications. He had developed Covid-19 pneumonia but that had gradually improved. I used to meet his daughter almost every day during the counseling sessions. She was always anxious and worried but those conversations were quite easy; but I found it really difficult to close even a short conversation with the patient. The conversation was paused by his rather long silences or perhaps simply by his disinterest in what I was trying to convey. We could never discuss anything beyond his ailments. Despite being irritable, I walked swiftly towards him, but had to sit down at the nurses' station as breathlessness struck me. I wondered if my life would ever be the same again after my own severe Covid-19 attack earlier. As these thoughts passed through my mind, I got up, tried to put on a smile and went to that particularly "indifferent" patient. I know I spoke with an artificially elated tone and forced smile, "'Your RT-PCR tests came back negative. I have already met your family downstairs. You will be shifted out today." There was a silence. This time it was even more awkward. I was not expecting that for sure.

I know he blinked, I was not sure if I saw his eyes becoming moist though. I was about to say something, but stopped. He leaned towards me and said, "I live in ........, come and have a meal with us when you visit the neighbourhood, any time" Taken a bit by surprise and tickled by sweat inside the PPE, I said jokingly "You haven't seen me, how will you know it's me?"

He said with a choked voice "I will know you by your eyes and voice."

A sense of peace descended on me. I do not remember, but maybe I smiled at him behind my foggy visor, and went to the next patient.

Acknowledgement: I would like to acknowledge the inputs of Dr Utpal Bora, Assistant Professor, Department of Psychiatry, Gauhati Medical College and Hospital, in the final draft of the manuscript.

Conflicts of interests and funding: None declared 